\title{
Size-dependent anaerobic digestion rates of flocculated activated sludge: Role of intrafloc mass transfer resistance
}

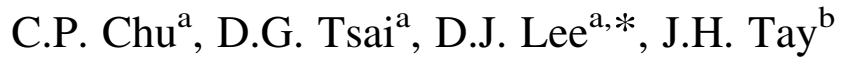 \\ ${ }^{a}$ Chemical Engineering Department, National Taiwan University, Taipei, 106, Taiwan, ROC \\ ${ }^{\mathrm{b}}$ Division of Environmental and Water Resources Engineering, School of Civil and Structural Engineering, Nanyang Technological University, \\ Singapore 639798, Singapore
}

Received 16 May 2004; accepted 21 January 2005

\begin{abstract}
The anaerobic digestion rate for flocculated sludge has been considered to be lower than that of original sludge, particularly in the later stages of digestion; Chu et al. (2003) attributed this relatively slower rate to the increased mass transfer resistance for reactants through the large flocs after flocculation. This study confirmed that methane production was retarded by flocculation. The structure of the floc was identified with fluorescence in situ hybridization (FISH) and a confocal laser scanning microscope (CLSM) technique. To verify the mass transfer resistance induced by flocculation, microsensors were applied to assess the response of oxygen concentration distribution inside the flocs that are subjected to sudden changes in ambient oxygen levels. Response time for the electrode at a floc's center was five times greater than the response time in original sludge flocs. Although the effective diffusivity of oxygen in the floc increased by 2.3 times after flocculation, the increased size of the flocculated floc was the major contributor to the total mass transfer resistance to oxygen.

(C) 2005 Elsevier Ltd. All rights reserved.
\end{abstract}

Keywords: Anaerobic digestion; Activated sludge; Mass transfer resistance; CLSM

\section{Introduction}

Sludge flocs are microreactors that adsorb and decompose pollutants. However, knowledge of the complex geometrical morphology and microbiological ecology inside flocs is far from comprehensive. This field has attracted considerable academic interest ( $\mathrm{Li}$ and Ganczarczyk, 1989; Zartarian et al., 1994; Jorand et al., 1995; Sanin and Vesilind, 1996). Detailed knowledge of floc structure is required to better understand sludge processes (Chung and Lee, 2003, Chung et al., 2003). Zartarian et al. (1997) and Thill et al. (1998) employed the fluorescence in situ hybridization (FISH) and confocal laser scanning microscope (CLSM) techniques to analyze the interior structure of flocs. Chu and Lee (2004a,b) and Chu et al. (2004) applied

\footnotetext{
* Corresponding author. Tel.: +88622362 5632; fax: +88622302 3040 .

E-mail address: djlee@ccms.ntu.edu.tw (D.J. Lee).
}

0301-4797/\$ - see front matter (C) 2005 Elsevier Ltd. All rights reserved. doi:10.1016/j.jenvman.2005.01.022 this technique to explore the interior structures of activated sludge flocs.

Microsensors have been employed to evaluate microenvironments in microbial communities (Revsbech and Jorgensen, 1986), particularly microbial communities in biofilms (Revsbech et al., 1989; Kuhl and Jorgensen, 1992; Schramm et al., 1996; Zhang and Bishop, 1994; Yu and Bishop, 1999, 2001; Bishop and Yu, 1999; Li and Bishop, 2002). Recently the microelectrode technique has also been widely applied to assess the micro-transport processes in an activated sludge floc (De Beer et al., 1998; Schramm et al., 1999a,b; Ploug and Jorgensen, 1999; Li and Bishop, 2004).

Anaerobic digestion is typically utilized as a stabilization technique to reduce the volume of waste activated sludge and produce bio-gas. Moreover, chemical flocculants are often utilized prior to sludge dewatering to enhance filtration rates. Although the dosage of polyelectrolyte in sludge is usually low, Dentel et al. (2000) demonstrated that the applied polyelectrolyte attached to and was carried out with the conditioned sludge at an amount up to $10 \mathrm{~kg} / \mathrm{ton}$ dry solids (DS). Contradictory results have been reported regarding the effect of chemical conditioners on anaerobic digestion of sludge. Gossett et al. (1978) measured reduced 
methane production and the volatile solid destruction ratio of anaerobically digested wastewater sludge when organic coagulants were present. El-Mamouni et al. (1998) observed that the synthetic polyelectrolyte did not inhibit biomass activity, but enhanced the metabolite transfer rate and reduced the inhibitory effects of acetogenic and methanogenic bacteria in a UASB reactor. Chu et al. (2003) reported that the digestion rate of sludge flocculated with a cationic polymer was higher than for original sludge during the initial phase of digestion, attributable to the additional carbon source provided by the polymer. However, the digestion rate for flocculated sludge soon declined and became less productive than the original sludge during the later stage of digestion. Since flocculation considerably increased floc size, the authors speculated that the mass transfer resistance accounted for the reduced digestion rate in the flocculated sludge. However, further experimental evidence is required to confirm these speculative ideas.

By combining FISH/CLSM and a microsensor technique, this work demonstrated that the increase in total mass transfer resistance after polyelectrolyte flocculation was mainly attributable to the increased floc size.

\section{Experimental}

\subsection{The samples}

Waste-activated sludge was obtained from the wastewater treatment plant of the Neili Bread Plant of Presidential Enterprise Co., Taoyuan, Taiwan. The chemical oxygen demand (COD), suspended solids (SS) and turbidity data for the supernatant in the sludge, analyzed by adopting EPA Taiwan standard methods, were $0.0067 \mathrm{~kg} \mathrm{~m}^{-3}$ (COD), $0.0088 \mathrm{~kg} \mathrm{~m}^{-3}$ (SS) and $2.4 \mathrm{NTU}$ (turbidity). The sludge sample was sludge sediment obtained after a $1 \mathrm{~h}$ settling period. The total solid content of the sludge was measured at $10.30 \mathrm{~kg} \mathrm{~m}^{-3}$. The $\mathrm{pH}$ value of the original sludge was approximately 6.7 .

Cationic polyelectrolyte T3052, obtained from Kai-Guan Inc., Taiwan, is a polyacrylamide with a molecular weight of $10^{7}$ and surface charge of $2.27 \mathrm{meq} / \mathrm{g}$. The sludge sample was first placed in a mixing unit, which was a 1-L baffled mixing chamber equipped with a paddle mixer. The mixer had a variable-speed motor directly connected to a torquemeter. Flocculant solution $(0.2 \%$ by weight $)$ was then gradually poured into the mixing chamber while stirring first at $200 \mathrm{rpm}$ for $300 \mathrm{~s}$, and then at $50 \mathrm{rpm}$ for a further $1200 \mathrm{~s}$. The polyelectrolyte flocculation did not significantly alter the $\mathrm{pH}$ value of the sludge sample.

\subsection{Digestion and test}

The anaerobic digestion of sludge followed the procedure outlined by Chu et al. (2003). Eight $\mathrm{ml}$ of sludge (original or flocculated) was mixed with $1 \times 10^{-6} \mathrm{~m}^{3}$ of anaerobe strains isolated by Chang et al. (1996) and $1 \times 10^{-6} \mathrm{~m}^{3}$ of medium (with a composition of $0.35 \mathrm{~g} / \mathrm{L}$ of $\mathrm{K} 2 \mathrm{HPO} 4,270 \mathrm{mg} / \mathrm{L}$ of $\mathrm{KH}_{2} \mathrm{PO}_{4}, 2.7 \mathrm{~g} / \mathrm{L}$ of $\mathrm{NH}_{4} \mathrm{Cl}$, $100 \mathrm{mg} / \mathrm{L}$ of $\mathrm{CaCl}_{2} \cdot 2 \mathrm{H}_{2} \mathrm{O}, 100 \mathrm{mg} / \mathrm{L}$ of $\mathrm{MgCl}_{2} \cdot 2 \mathrm{H}_{2} \mathrm{O}$, $20 \mathrm{mg} / \mathrm{L}$ of $\mathrm{FeCl}_{2} \cdot 6 \mathrm{H}_{2} \mathrm{O}, 12 \mathrm{~g} / \mathrm{L}$ of yeast extract, and $1 \mathrm{mg} / \mathrm{L}$ of reszurin) and digested at $35^{\circ} \mathrm{C}$. Triplicate testing was performed for each sample to ensure data reproducibility.

A particle sizer (LS230, Coulter) measured floc size with a light scattering method. The mean floc size of the original sludge was $60 \mu \mathrm{m}$. Methane production was quantified with a gas chromatograph (Sigma 3B Perkin-Elmer) equipped with a packed column $(200 \times 0.5 \mathrm{~cm}, 80 / 100$ Porapak Q; Supecol, Bellefonte, PA) and a flame-ionization detector. Column temperature was maintained at $90{ }^{\circ} \mathrm{C}$ and the injector and detector were maintained at $55^{\circ} \mathrm{C}$. Nitrogen, with a flow rate of $3.33 \times 10^{-7} \mathrm{~m}^{3} \mathrm{~s}^{-1}$, was employed as the carrying gas. An integrator (HP3396 Series II) was utilized to measure the methane concentration.

A confocal laser scanning microscope (CLSM) (OLYMPUS BX50) was employed to observe the internal structure of the sludge floc. The microscope was equipped with an image processor (OLYMPUS FV5 PSU) and an Argon laser source to stimulate fluorescence. A $10 \times$ objective and the software FLUOVIEW version 3.0 were utilized for imaging the sludge floc. Samples were scanned with the microscope at a fixed depth. A digitized image of the sludge floc was then obtained. Sludge samples for CLSM analysis were first fixed with $3 \%$ paraformaldehyde in phosphate buffer saline. The fixed sample was then embedded in agar that has low melting point (melting point of $75^{\circ} \mathrm{C}$ and gelling point of $38^{\circ} \mathrm{C}$ ) for FISH. This research employed two different DNA probes, Eub 338 (nucleotide sequence 5'-GCTGCCTCCCGTAGGAGT-3' labeled by rhodamine and Arc 915 (nucleotide sequence 5'-GTGCTCCCCCGCCAATTCCT-3', labeled by tetrachlorofluorescein, to identify, respectively, eubacteria and Archaea, the most common methanogenic bacteria in the sludge (Chu and Lee, 2004a). The stained samples were washed three times with hybridization buffer solution to remove excess probes.

A $10-\mu \mathrm{m}$ diameter DO microelectrode (DO-10, Unisense, Denmark) was employed to evaluate the oxygen transport within both the original and flocculated flocs. The measurement of oxygen levels was based on diffusion of oxygen through a silicone membrane to an oxygen reducing cathode that is polarized against an internal $\mathrm{Ag} / \mathrm{AgCl}$ anode. A micromanipulator was adopted to finely adjust the position of the electrode tip in the exact center of the floc, at a spatial resolution better than $20 \mu \mathrm{m}$. The stirring sensitivity of the sensor is less than $2 \%$, and its response time $(90 \%)$ is $1-3 \mathrm{~s}$. The output of the sensor was recorded continuously by a picoammeter (PA2000, Unisense, Denmark) and a personal computer. A flow chamber was devised to physically keep the sludge floc in a stream of flowing water. Air aeration $(210 \mu \mathrm{mol} / \mathrm{L})$ was applied to 
saturate the flowing water (stream 1) with oxygen. The incoming fluid was then switched to stream 2, which was de-oxygenized by applying nitrogen gas sparging. The DO level at the floc's center was recorded over time. After the DO level reached a low plateau value of about $80 \mu \mathrm{mol} / \mathrm{L}$, the incoming stream was switched back to stream 1 and the DO level at the floc center increased again.

\section{Results and discussion}

\subsection{Methane production}

The amount of methane produced by digestion serves as a useful index to evaluate a sludge's biodigestability. Triplicate tests confirmed that the relative deviations of the methane production data were under $3 \%$, as shown in Table 1.

The digestion rate of sludge flocculated at dosages greater than $15 \mathrm{~g} / \mathrm{kg}$ DS declined over time. After 10 days of digestion, the methane production curves for the original and the flocculated sludges at dosages under $5 \mathrm{~g} / \mathrm{kg}$ DS converged. For example, after 40 days of digestion, the amounts of methane produced for original and $5 \mathrm{~g} / \mathrm{kg}$ flocculated sludge were $136 \mathrm{~g}-\mathrm{CH}_{4} / \mathrm{kg} \quad \mathrm{DS}$ and $132 \mathrm{~g}-\mathrm{CH}_{4} / \mathrm{kg} \mathrm{DS}$, respectively; these values could be considered identical. The corresponding amounts of methane produced by $15 \mathrm{~g} / \mathrm{kg}$ DS flocculated sludge and

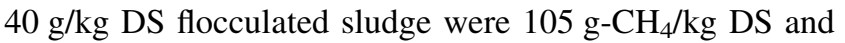
$85 \mathrm{~g}-\mathrm{CH}_{4} / \mathrm{kg}$ DS, respectively; these figures corresponded to 23 and $38 \%$ reductions in methane yield from the original sludge, respectively. This difference is significant at a confidence level of $95 \%$.

These experimental results for sludge digestion correlate with the conclusions obtained by Chu et al. (2003). That is, the flocculants enhanced the efficiency during the first stage of digestion (El-Mamouni et al., 1998), but inhibited digestion if the sludge was conditioned with a high dosage of cationic polymer (Gossett et al., 1978). This study, thus, showed that flocculants have different roles during different stages of digestion. Moreover, since the methane production rate for the flocculated sludge was higher than that of the original sludge, the flocculant had negligible toxicity to the microbial population (Chu et al., 2003). The retardation of the methane production by $\mathrm{T}-3052$ flocculated sludge observed over the later stages of digestion was not attributable to chemical toxicity effects.

\subsection{Change in floc size}

Table 1 lists the mean floc sizes in the original and flocculated sludges. The floc size of the original sludge flocculated with cationic polymer T3052 increased from $57 \mu \mathrm{m}$ to $400 \mu \mathrm{m}$ at a dosage of $40 \mathrm{~g} / \mathrm{kg} \mathrm{DS}$, suggesting favorable flocculation.

The floc size decreased as digestion proceeded, implying a deterioration of the floc's structure. The size of the original sludge floc decreased only slightly, that is, from 58 to $51 \mu \mathrm{m}$ following 40 days of anaerobic digestion. However, a dramatic reduction in the sizes of the sludge flocs was noticeable for the T-3052 flocculated samples. For example, the floc size of $40 \mathrm{~g} / \mathrm{kg}$ DS flocculated sludge decreased by more than $55 \%$ during the first 10 days of digestion. The corresponding floc size of sludge flocculated with $15 \mathrm{~g} / \mathrm{kg}$ DS also decreased from 190 to $135 \mu \mathrm{m}$. The floc size changed only slightly in subsequent digestion stages. On the 40th day of digestion, the T-3052 flocculated flocs remained three times larger than the original sludge flocs. The size reduction was less significant in cases in which a lower dosage of $5 \mathrm{~g} / \mathrm{kg}$ DS was applied.

The large floc size correlates with the reduced digestion efficiency for the T3052-flocculated sludge. Mass transfer resistance is therefore, proposed to explain the sizedependent digestion efficiency, as shown in Table 1. During anaerobic digestion, the sludge is first hydrolyzed into small molecules, such as acetic acids or other long-chain organic acids (acidogenic stage). These long-chain compounds are then decomposed to form methane (methanogenic stage). The large floc size of T3052-floculated sludge prohibited efficient species' movement within the floc, and hindered the subsequent acidogenic and methanogenic stages that produce methane.

\subsection{Floc imaging}

Fig. 1 shows two CLSM images from the original- and T3052-flocculated sludge flocs (15 g/kg DS). The staining of bacteria highlighted the position of the solid phase. A loose interior was confirmed in the CLSM image of the original sample. The floc contained both small and large

Table 1

Change in methane production and floc size during anaerobic digestion

\begin{tabular}{|c|c|c|c|c|c|c|c|c|}
\hline \multirow[t]{2}{*}{ Time (d) } & \multicolumn{2}{|l|}{ Original sludge } & \multicolumn{2}{|l|}{$5 \mathrm{~g} / \mathrm{kg} \mathrm{DS}$} & \multicolumn{2}{|l|}{$15 \mathrm{~g} / \mathrm{kg} \mathrm{DS}$} & \multicolumn{2}{|l|}{$40 \mathrm{~g} / \mathrm{kg} \mathrm{DS}$} \\
\hline & $\mathrm{CH}_{4}(\mathrm{~g} / \mathrm{kg} \mathrm{DS})$ & $d_{f}(\mu \mathrm{m})$ & $\mathrm{CH}_{4}(\mathrm{~g} / \mathrm{kg} \mathrm{DS})$ & $d_{f}(\mu \mathrm{m})$ & $\mathrm{CH}_{4}(\mathrm{~g} / \mathrm{kg} \mathrm{DS})$ & $d_{f}(\mu \mathrm{m})$ & $\mathrm{CH}_{4}(\mathrm{~g} / \mathrm{kg} \mathrm{DS})$ & $d_{f}(\mu \mathrm{m})$ \\
\hline 0 & 0 & 60 & 0 & 140 & 0 & 190 & 0 & 400 \\
\hline 6 & 41 & 60 & 60 & 118 & 48 & 143 & 46 & 232 \\
\hline 12 & 83 & 59 & 77 & 116 & 69 & 120 & 55 & 181 \\
\hline 20 & 115 & 57 & 98 & 100 & 81 & 100 & 69 & 180 \\
\hline 30 & 131 & 57 & 120 & 98 & 85 & 101 & 77 & 172 \\
\hline 60 & 144 & 54 & 137 & 94 & 100 & 96 & 80 & 160 \\
\hline
\end{tabular}




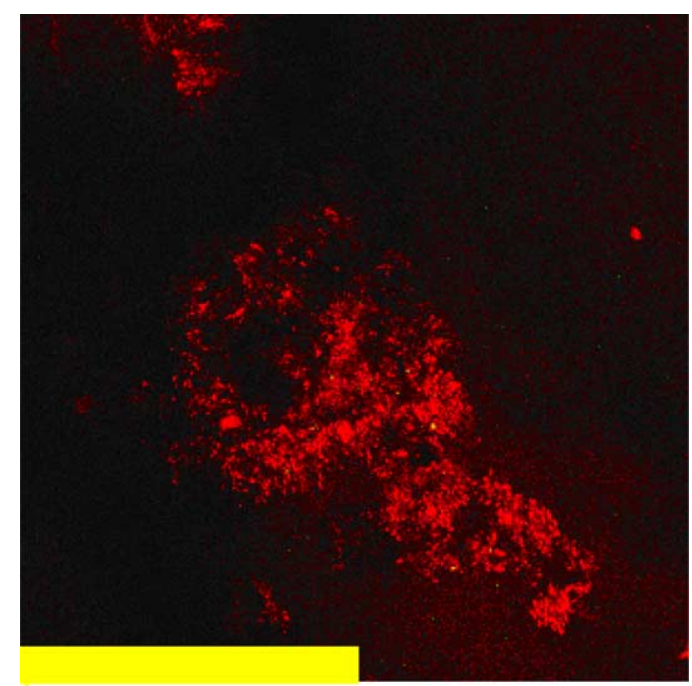

(a)

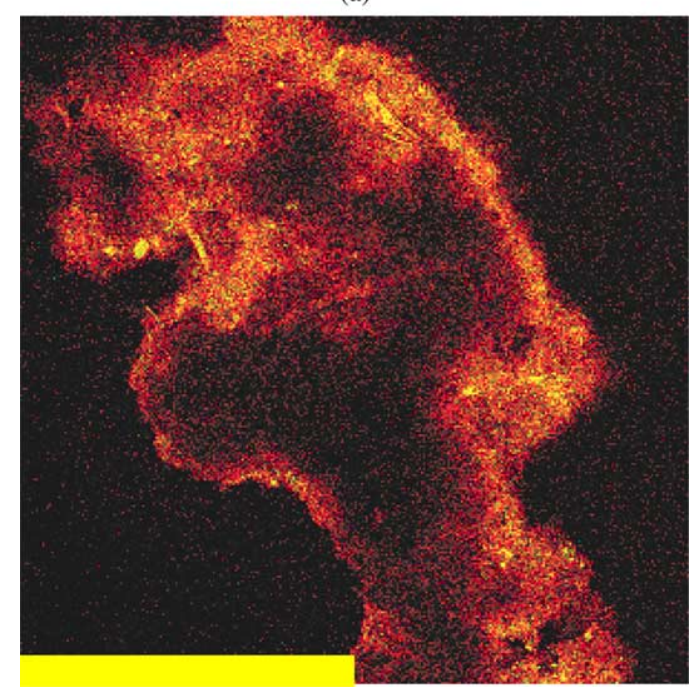

(b)

Fig. 1. Images from confocal laser scanning microscope. (a) Original sludge floc, (b) T3052-flocculated sludge floc.

voids. The interiors of the flocculated flocs had minimal amounts of fluorescence light, likely a result of the light extinction effect deep in the floc interior.

\subsection{DO response}

Fig. 2 shows the DO responses for the original- and the T3052-flocculated flocs (15 g/kg DS). Time scales were moved to meet the origin to demonstrate the difference in the DO responses. The assessment of original floc $(100 \mu \mathrm{m})$ verified that the response time for DO to decline from high to low levels was roughly $2 \mathrm{~s}$, close to the response time of the electrode (1-3 s). The response time for the electrode at the floc's center increased to $10 \mathrm{~s}$. A finite, but small, mass transfer resistance was thereby identified for the original sludge floc.

For the flocculated floc with a diameter of $300 \mu \mathrm{m}$, the response times for both the DO-increasing and-decreasing stages were 12-20 s, about 20-100\% longer than the response times for the original floc. Since the flocculated floc had a diameter three times that of the original floc, the response time of the flocculated floc should be nine times that of the original floc, if molecular diffusion were the sole controlling factor with a constant diffusivity. The not-solong response time noted for the flocculated floc demonstrated that the diffusivities for original and flocculated flocs might be different.

Assume that the oxygen transfer in a floc can be modeled as a process that occurs in a porous sphere of radius $r_{f}$ and an effective diffusivity of $D$. Then the concentration evolution at the center of the sphere, if the surrounding oxygen concentration was suddenly changed from $C_{0}$ to $C_{1}$ at $t=0$, can be stated as

$\ln \left[\frac{1}{2} \frac{C_{0}-C}{C_{0}-C_{1}}\right]=-\frac{\pi^{2} D}{r_{f}^{2}} t$

Fig. 3 shows the model fitting results for the original floc and for the flocculated floc, with the best-fit slopes identified as -0.286 and -0.215 , respectively. The effective diffusivities of oxygen in the floc interior are estimated at $2.9 \times 10^{-10}$ and $1.97 \times 10^{-9} \mathrm{~m}^{2} / \mathrm{s}$, respectively. That is, the effective diffusivity for the flocculated floc was determined to be close to the value proposed by Li and Bishop (2004), i.e. about $20 \%$ lower than that in water $\left(2.24 \times 10^{-9} \mathrm{~m}^{2} / \mathrm{s}\right)$. Conversely, the diffusivity of oxygen in the original floc was much lower than in the flocculated floc, only about $13 \%$ of the level of oxygen in pure water. Chu et al. (2004b) recently demonstrated that internal pores of flocculated flocs are considerably larger than those in original flocs. In this work, the effective diffusivity of the original floc increased by 2.3 times after flocculation. This experimental finding correlates with the conclusions obtained by Chu and Lee (2004b).

The mean floc sizes in anaerobic digestion were $60 \mu \mathrm{m}$ for the original flocs and $400 \mu \mathrm{m}$ for the $40 \mathrm{~g} / \mathrm{kg} \mathrm{DS}$ flocculated flocs, as shown in Table 1. With a higher diffusivity, the flocculated flocs still exhibited a higher overall mass transport resistance $\left(\propto r_{f}^{2} / D\right)$ than the original flocs, a result of the larger size of the original flocs. This experimental observation supports the speculations made by Chu et al. (2003) that mass transfer resistance hinders the anaerobic digestion process in well-flocculated flocs. The oxygen in the original flocs easily penetrated the floc, owing to its small floc size that, thereby, presented negligible intrafloc mass transfer resistance. During anaerobic digestion, large hydrolyzed molecules diffused into the floc and were further degraded by embedded bacteria. These large molecules required more time to transfer within floc than did oxygen.

Another rationale explaining the identified delayed methane production could be the coverage of bacteria surfaces by a polymer network, as proposed by Chatellier et al. (2001). Further work is needed to quantitatively 


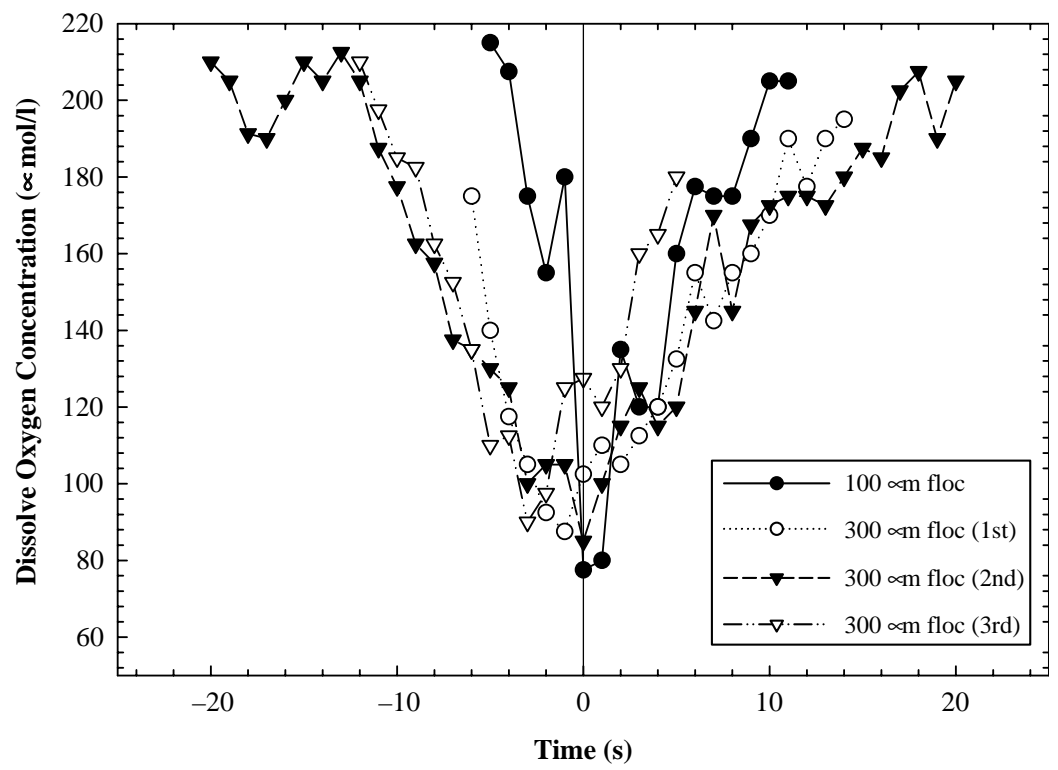

Fig. 2. Dissolved oxygen responses of original and T3052-flocculated sludge flocs.

estimate this effect in the intrafloc transport/reaction processes.

\section{Conclusion}

This work examined the possible role of mass transfer of species in the anaerobic digestion rate of flocculated sludge. Batch digestion tests were conducted with original and flocculated sludge, and the changes in the interior structure of flocculated sludge flocs were evaluated with fluorescence in situ hybridization (FISH) and confocal laser scanning microscope (CLSM) techniques. The ease of oxygen transport within flocs was assessed with a microelectrode technique.

Flocculation markedly increased floc size. Correlating with the observations by Chu et al. (2003), the production of methane by $15 \mathrm{~g} / \mathrm{kg}$ DS flocculated sludge and $40 \mathrm{~g} / \mathrm{kg}$ DS flocculated sludge was reduced by 23 and $38 \%$, respectively. The large floc size correlated with the reduced digestion efficiency for the T3052-flocculated sludge. The CLSM images demonstrated that the interior of the flocculated flocs had minimal fluorescent light. Based on the microelectrode technique it was estimated that the diffusivity of oxygen in well-flocculated flocs was 2.3 times greater than that in original flocs. However, since the floc

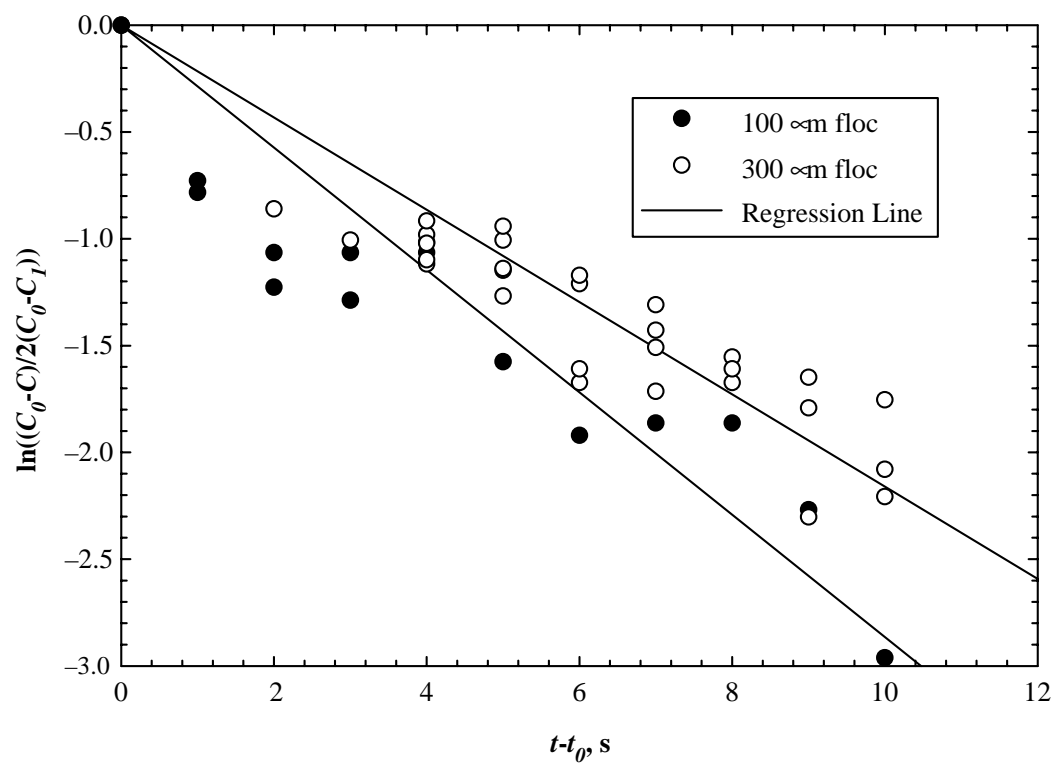

Fig. 3. Model fitting to determine the slopes of regression lines. 
size of the flocculated sludge was five times that of the original floc during the anaerobic digestion test, the former still had greater total mass transfer resistance than the original floc.

\section{Acknowledgements}

National Science Council of ROC financially supported this work. The assistance from Dr Stephen Tay Tiong Lee and Dr Volodymyr Ivanov of Nanyang Technological University, Singapore, for CLSM analysis is highly appreciated. The suggestion by a reviewer on the use of simplified mass transfer model to correlate the experimental data was appreciated.

\section{References}

Bishop, P.L., Yu, T., 1999. A microelectrode study of redox potential change in biofilm. Water Science and Technology 39 (7), $179-185$.

Chatellier, X., Bottero, J.Y., Le Petit, J., 2001. Adsorption of a cationic polyelectrolyte on Escherichia coli bacteria: 1.adsorption of the polymer. Langmuir 17, 2782-2790.

Chu, C.P., Lee, D.J., 2004a. Bilevel thresholding of image of sludge flocs. Environmental Science and Technology 38 (4), 1161-1169.

Chu, C.P., Lee, D.J., 2004b. Multiscale structures of biological flocs. Chemical Engineering Science 59 (8-9), 1875-1883.

Chu, C.P., Lee, D.J., Tay, J.H., 2005. Floc Model and in trafloc flow. Chemical Engineering Science 60(2), 565-575.

Chu, C.P., Lee, D.J., Chang, B.V., You, C.H., Liao, C.S., Tay, J.H., 2003. Anaerobic digestion of polyelectrolyte flocculated waste activated sludge. Chemosphere 53, 756-764.

Chu, C.P., Lee D.J., Peng, X.F., 2004. Structure of conditioned sludge flocs, Water Research 38(9), 2125-2134.

Chung, H.Y., Lee, D.J., 2003. Porosity and floc structure of flocculated waste activated sludge floc. Journal of Colloid and Interface Science 267, 136-143.

Chung, H.Y., Ju, S.P., Lee, D.J., 2003. Hydrodynamic drag force exerted on waste activated sludge floc. Journal of Colloid and Interface Science 263, 498-505.

De Beer, D., Schramm, A., Santegoeds, M.C., Nielsen, K.H., 1998. Anaerobic processes in activated sludge. Water Science and Technology 37 (4-5), 605-608.

Dentel, S.K., Chang, L.L., Raudenbush, D.R., Junnier, R.W., AbuOrf, M.M., 2000. Influence of polymer chemistry on biosolids and the environment. Water Environment Research Foundation, Alexandria, VA.

El-Mamouni, R., Leduc, R., Guiot, S.R., 1998. Influence of synthetic and natural polymers on the anaerobic granulation process. Water Science and Technology 38 (8-9), 341-347.

Gossett, J.M., McCarty, P.L., Wilson, J.C., Evans, D.S., 1978. Anaerobic digestion of biosolids from chemical treatment. Research Journal of Water Pollution Control Federation 50, 533-542.
Jorand, F., Zartarian, F., Thomas, F., Block, J.C., Bottero, J.Y., Villemin, G., Urbain, V., Manem, J., 1995. Chemical and structural (2D) linkage between bacteria within activated sludge flocs. Water Research 29, 1639-1647.

Kuhl, M., Jorgensen, B.B., 1992. Microsensor measurements of sulfate reduction and sulfide oxidation in compact microbial communities of aerobic biofilm. Applied and Environmental Microbiology 58, 11641174.

Li, D.H., Ganczarczyk, J.J., 1989. Fractal geometry of particle aggregates generated in water and wastewater treatment processes. Environmental Science and Technology 23, 1385-1389.

Li, J., Bishop, P.L., 2002. In situ identification of azo dye inhibition effects on nitrifying biofilms using microelectrodes. Water Science and Technology 46 (1-2), 207-215.

Li, B., Bishop, P.L., 2004. Microprofiles of activated sludge floc determined using microelectrodes. Water Research 38, 1248-1258.

Ploug, H., Jorgensen, B.B., 1999. A net-jet flow system or mass transfer and microsensor studies of sinking aggregates. Marine Ecology Progress Series 176 (1), 279.

Revsbech, N.P., Christensen, P.B., Nielson, L.P., Sorensen, J., 1989. Denitrification in a trickling filter biofilm studies by a microsensor for oxygen and nitrous oxide. Water Research 23 (7), 867.

Revsbech, N.P., Jorgensen, B.B., 1986. Microelectrodes-Their use in microbial ecology. Advances in Microbial Ecology 9, 293-352.

Sanin, F.D., Vesilind, P.A., 1996. Synthetic sludge: a physical/chemical model in understanding bioflocculation. Water Environment Research 68, 927-933.

Schramm, A., Larsen, L.H., Revsbech, P.N., Ramsing, B.N., Amann, R., Schleifer, H.K., 1996. Structure and function of a nitrifying biofilm as determined by in situ hybridization and the use of microelectrodes. Applied and Environmental Microbiology 62, 4641-4647.

Schramm, A., De Beer, D., Heuvel, J.C., Ottengraf, S., Amann, R., 1999a. Microscale distribution of populations and activities of Nitrosospira and Nitrispira spp. along a macroscale gradient in a nitrifying bioreactor: quantification by in situ hybridization and the use of microsensors. Applied and Environmental Microbiology 65 (8), 3690-3696.

Schramm, A., De Beer, D., Wagner, M., Amamm, R., 1999b. Identification and activities in situ of Nitrosospira and Nitrospira spp. As dominant population in a nitrifying fluidized bed reactor. Applied and Environmental Microbiology 64, 3480-3485.

Thill, A., Veerapaneni, S., Simon, B., Wiesner, M., Bottero, J.Y., Snidaro, D., 1998. Determination of structure of aggregates by confocal scanning laser microscopy. Journal of Colloid and Interface Science 204, 357-362.

Yu, T., Bishop, P.L., 1999. A microelectrode study of redox potential change in biofilms. Water Science and Technology 39 (7), 179-185.

Yu, T., Bishop, P.L., 2001. Stratification and redox potential change in an aerobic and sulfate-reducing biofilm studied using microelectrodes. Water Environmental Research 73, 368-373.

Zartarian, F., Mustin, C., Bottero, J.Y., Villemin, G., Thomas, F., Ailleres, L., Chaampenois, M., Grulois, P., Manem, J., 1994. Spatial arrangement of the component of activated sludge flocs. Water Science and Technology 30 (11), 243-250.

Zartarian, F., Mustin, C., Villemin, G., Ait-Ettager, T., Thill, A., Bottero, J.Y., Mallet, J.L., Snidaro, D., 1997. Three-dimensional modeling of an activated sludge floc. Langmuir 13, 35-40.

Zhang, T.C., Bishop, P.L., 1994. Experimental determination of the dissolved oxygen boundary layer and mass transfer resistance near the fluid-biofilm interface. Water Science and Technology 30 (11), 47-58. 